\title{
Advances in selective activation of muscles for non-invasive motor neuroprostheses
}

\author{
Aikaterini D. Koutsou ${ }^{1 *}$, Juan C. Moreno ${ }^{1}$, Antonio J. del Ama ${ }^{2}$, Eduardo Rocon ${ }^{3}$ and José L. Pons ${ }^{1}$
}

\begin{abstract}
Non-invasive neuroprosthetic (NP) technologies for movement compensation and rehabilitation remain with challenges for their clinical application. Two of those major challenges are selective activation of muscles and fatigue management. This review discusses how electrode arrays improve the efficiency and selectivity of functional electrical stimulation (FES) applied via transcutaneous electrodes. In this paper we review the principles and achievements during the last decade on techniques for artificial motor unit recruitment to improve the selective activation of muscles. We review the key factors affecting the outcome of muscle force production via multi-pad transcutaneous electrical stimulation and discuss how stimulation parameters can be set to optimize external activation of body segments. A detailed review of existing electrode array systems proposed by different research teams is also provided. Furthermore, a review of the targeted applications of existing electrode arrays for control of upper and lower limb NPs is provided. Eventually, last section demonstrates the potential of electrode arrays to overcome the major challenges of NPs for compensation and rehabilitation of patient-specific impairments.
\end{abstract}

Keywords: sFES, Muscle selectivity, Muscle fatigue, Multi-pad electrodes, Neuroprosthesis

\section{Background}

A new generation of orthotic and prosthetic devices has started to include active elements capable of providing (or removing) energy to compensate and enhance human function. In this regard, the application of human muscles as actuators of orthotic systems by surface Functional Electrical Stimulation (sFES) is a promising technology [1]. FES systems were introduced as a method to externally activate the sensory-motor system in case of central nervous system (CNS) lesion [2, 3]. FES systems can be applied as motor neuroprostheses of motor functions for recovery in stroke patients $[4,5]$ or as means for compensation in assistive technologies, for example for control of walking and grasping after spinal cord injury (SCI) [6] or tremor suppression [7]. In general, available sFES systems for motor neuroprostheses face two major limitations, in addition to skin irritation and pain: a) insufficient selective activation of muscles and b) muscle fatigue as a reaction to muscle

\footnotetext{
* Correspondence: aikaterini.koutsou@csic.es

${ }^{1}$ Neural Rehabilitation Group, Cajal Institute, Spanish National Research

Council, Madrid, Spain

Full list of author information is available at the end of the article
}

stimulation [8]. These two challenges remain open and the goal of this review is to assess the recent progress of research groups to overcome these limitations.

Consequently, the following question arises: How can selective and less fatiguing muscle activation be achieved with surface electrode arrays The review of the literature in this article is aimed to answer this question, providing a detailed revision of the state-of-the-art on selective sFES technology, their benefits, advantages and challenges. This work aims to revise both the available surface electrode arrays and the applied control strategies on this kind of sFES applications. The structure of this article is the following. Functional electrical stimulation and selectivity section provides an overview of the theoretical basis of sFES activation; feasibility of selective muscle activation through sFES is discussed. In Electrodes for muscle activation selectivity section novel solutions to design surface electrodes to improve muscle selectivity are revised. Selective control of muscle activation section presents a list of candidate applications of surface array electrodes in motor rehabilitation while Discussion section discusses in detail the current technology applied in most relevant 
available systems that address selective activation of muscles. Finally, conclusions are presented in Conclusions section.

\section{Methods}

The studies included in this review are the result of a search in electronic literature and international congress proceedings. Electronic libraries such as SCOPUS, ScienceDirect, PubMed and IEEE Xplore were used. Proceedings from international congress EMBS, IFESS, NER, ICNR and ICORR were also included. The search criteria were studies that presented in decade 2003 to 2014. The keywords were "muscle selectivity", "electrode array", "sFES", "multi-pad electrodes", "muscle fatigue", the inclusion criteria were:

- Studies presented a new electrode array system

- Use of electrode arrays or small electrodes grouped as an array in order to study muscle selectivity or fatigue.

- Stimulation strategy in muscle fatigue studies had to be asynchronous activation of each element of the array.

- FES had to be superficial and not implanted

- sFES application could be on forearm muscles or lower limb knee or plantar flexors/extensors

\section{Review}

\section{Functional electrical stimulation and selectivity}

Conventional surface electrodes that are individually applied to muscles are more suitable for stimulation of relatively large muscles that are close to the skin. However, such individual electrodes are limited to deliver stimulation to deeper muscles and to achieve fine control of groups of muscles [3]. As a result, selectivity needs to be significantly improved for applications of sFES to control the movements that involve multiple muscles or muscles that not innervate close to the skin. A classical example is the control of forearm movement, in which muscles are activated to generate forces at fingers and wrist joint [9]. In this context, several factors influence the quality of the movement induced by sFES. The movement generated by sFES with traditional electrodes depends on the position and the size of the cathode electrode [10], mainly due to the "overflow" phenomenon. The "overflow" phenomenon is described as the excitation of muscles that are adjacent to the target muscle, which results in undesired elicited movements. Additionally, size and type of the sFES electrode influence the pain threshold as well as the motor threshold of the stimulation $[10,11]$. Current approaches to minimize the overflow phenomenon are based on invasive electrodes placed over (epimysial), around (cuff) or inside (intramuscular) the target muscle [8]. However, this type of electrodes requires a surgical procedure to be inserted into the target muscles. There are also alternative solutions based on percutaneous electrodes, which are placed in the target muscle without surgical procedures, although the risk of an infection is still high [8]. In summary, due to their invasive nature and possible medical complications, clinicians and patients are prone to avoid such type of electrodes. In contrast to this solution, transcutaneous electrodes are characterized by fast, non-invasive and simple use, which increases their acceptability by end-users.

Muscle activation selectivity can be achieved with conventional stimulation electrodes as long as the electric field generated under the electrode is adequately controlled. The modulation of the resulting electric field generated under the surface electrode that is aimed to reach the motor nerve and muscle fibers is a difficult task [12]. Current solutions control the stimulation parameters of the stimulator to achieve a moderation of the electric field generated under the surface of the electrode.

Another important challenge for the translation of sFES-based solution for clinical use is muscle fatigue. Muscle fatigue is defined as the progressive loss of capability of the stimulated muscle to be contracted [1]. In general, it can be said that muscle fatigue during artificial activation by sFES is developed faster if compared to physiological muscle activation. This is due to the fact that sFES technologies are not selective on muscle fibers recruitment since the stimulation applied at the skin surface recruits basically the same set of muscle fibers beneath a stable surface electrode, which is not the physiological approach for muscle contraction. Furthermore, although the negative effect of muscle fatigue induced by sFES is temporary, it is the main issue to achieve functional compensation or substitution of activities were muscle activation should be guaranteed for safety, such as standing or walking [3].

Over the last years, several studies have evaluated techniques for the mitigation of muscle fatigue during electrical stimulation. Muscle fatigue strategies can be separated in two main approaches: Closed-loop control strategies to control electrical stimulator parameters and advances in sFES electrodes' technology. Each category separated has demonstrated that muscle fatigue appearance can be delayed. However, we believe that the combination of the two categories could improve the outcomes of each one stand-alone. A number of control techniques have been proposed in the literature as approaches managing the appearance of muscle fatigue in surface stimulation. Among others, PID control [13], adaptive control [14], fuzzy logic [15], neural networks [16] and adaptive sliding mode control [17], have been reported as alternatives to delay muscle fatigue. For 
detailed reviews on the literature on such control techniques the reader is referred to $[18,19]$ and $[20]$. These control techniques aim to modulate muscle fiber temporal recruitment either by varying pulse temporal characteristics (such as inter-pulse intervals or train frequency) or by predictive models that account for fatigue to control the stimulation [21-27]. Other studies testing invasive approaches to address sFES-induced fatigue have shown that cuff electrodes also contribute to delay the appearance of muscle fatigue. The former result is explained by a high degree of spatial selectivity when directly and selectively stimulating nerve fibers, which in turn allows choosing when muscle fibers are recruited depending on the tripole that is activated [28]. However, the practical drawbacks of using cuff electrodes have been exposed previously [8].

Besides the difficulty of controlling the electric field generated beneath the electrodes, there are differences in muscle characteristics and fatigue properties after SCI. As a result of disruption in nerve activation, loss of muscle mass and transformation of muscle fiber to type II fast-twitch fibers is observed [29]. In addition, other three major differences between CNS and sFES motor unit recruitment have an influence on muscle fatigue [3]. The first difference is how motor units are recruited, in synchronous or asynchronous mode [30]. The second difference is the order of recruitment of the different muscle fibers types [31, 32]. More information about muscle fibers' types and their response can be found in the literature [33-37]. The third difference is that CNS fires action potentials that activate muscle fibers at a low frequency of $6-8 \mathrm{~Hz}$ [36]. In contrast, sFES requires frequencies of titanic contraction $(20 \mathrm{~Hz})$ or higher in order to avoid tremulous muscle contractions [36].

Recently, the scope of potential clinical applications of sFES has widened and with it, the required level of muscle activation selectivity and fatigue resistance. The former motivations and latest technology advantages have led to the development of new sFES systems that should ultimately achieve a variety of selective movements and delay muscle fatigue, by means of noninvasive surface electrode arrays.

\section{Electrodes for muscle activation selectivity}

Advances in electronics and electrode design in the last decade, have led to a number of sFES systems that are able to implement theoretical muscle contraction principles in sFES practice. These systems apply an electric field with irregular shape and size with the use of electrode arrays [38]. An electrode array consists of a set of small electrodes (also known as pads) arranged in an array [39]. These systems were firstly proposed as a solution to electrode misplacement over the muscle since these allow for the relocation of the stimulated area with a fixed physical electrode location [40]. Another advantage of the electrode array is the possibility to place both anode and cathode electrodes over a single array. In this way, the delivery of stimulation can be simplified since only one element (array) has to be placed over the human limb and less time is required to find the correct position of the electrode [40]. Each pad in one electrode array can be activated independently to control the spatial and temporal distribution of electrical current field [40] and hence the excitation of different motor units. In that way, the pads that are better located over the target muscle can be selectively activated to generate a specific target movement. The first study found in literature of this kind of electrodes was developed by Nathan R. in 1979 [41], he proposed the electrode belts that consisted of a row of electrodes that was positioned perpendicular to the forearm in order to achieve individual activation of forearm muscles. The work of Lawrence et al. [42], Kuhn. [39] and Keller et al. [40] marked a line for the direction of the following studies on muscle selectivity. They were the first to develop electrode arrays with the structure presented in this work and they study the design of the array, the current distributions under it by developing advanced wrist control systems.

To the best of our knowledge, eight different array electrodes have been presented in the literature until the date. We categorized the electrode arrays that we found in the literature as follows:

1) Plastic flexible substrate electrodes: Actitrode [12, 43], INTFES [44], Chen [45], HYPER, MUNDUS [46], made by flexible printed circuit board on a polycarbonate.

2) Other textile electrodes: Smart Electrode [42, 47] and Smartex [48], made by silver coated fibers embroidered into square elements arranged in an array.

A third innovative technique to manufacture electrode arrays was presented by Yang et al. [49]. A screenprinted flexible and breathable fabric electrode array (FEA) fabricated entirely by screen printing the active electrode array directly onto a standard fabric was employed in this design. The electrode array consisted of four printed functional layers. The solution is proposed to reduce the costs associated with the embroidery technique [50] and the conductive path constraints of weaving and knitting approaches $[48,51]$.

Table 1 contains details of material, electrode pads and sizes from above mentioned electrode arrays. The electrode pads were round shaped in Smart, Actitrode, Smartex, and Chen electrode arrays, while rectangular shape was preferred in INTFES (see Fig. 1), HYPER (see Figs. 3 and 4), Yang and MUNDUS electrode arrays. 
Table 1 Comparison of main features of electrode arrays found in literature

\begin{tabular}{|c|c|c|c|c|c|c|c|}
\hline Electrode array & Material & $\begin{array}{l}\text { Number } \\
\text { of pads }\end{array}$ & $\begin{array}{l}\text { Array's } \\
\text { structure }\end{array}$ & Pad's shape & Pad's size & Gap's size & $\begin{array}{l}\text { Electrode's } \\
\text { dimensions }\end{array}$ \\
\hline \multirow[t]{2}{*}{ Smart Electrode } & \multirow{2}{*}{$\begin{array}{l}\text { textile silver } \\
\text { coated fibres }\end{array}$} & 16-pads & $4 \times 4$ & \multirow[t]{2}{*}{ round } & \multirow[t]{2}{*}{$10 \mathrm{~mm} \times 10 \mathrm{~mm}$} & \multirow[t]{2}{*}{$2 \mathrm{~mm}$} & $5 \mathrm{~cm} \times 5 \mathrm{~cm}$ \\
\hline & & 64-pads & $8 \times 8$ & & & & $10 \mathrm{~cm} \times 10 \mathrm{~cm}$ \\
\hline \multirow[t]{2}{*}{ Actitrode } & \multirow{2}{*}{$\begin{array}{l}\text { plastic flexible } \\
\text { substrate }\end{array}$} & 24-pads & $6 \times 4$ & \multirow[t]{2}{*}{ round } & $1 \mathrm{~cm}$ & \multirow[t]{2}{*}{$0.9 \mathrm{~cm}$} & \multirow[t]{2}{*}{$8 \mathrm{~cm} \times 5 \mathrm{~cm}$} \\
\hline & & 12-pads & $6 \times 2$ & & $1.2 \mathrm{~cm}$ & & \\
\hline INTFES (by Tecnalia) & $\begin{array}{l}\text { plastic flexible } \\
\text { substrate }\end{array}$ & 16-pads & $4 \times 4$ & oval, rectangular & & $2 \mathrm{~mm}$ & \\
\hline Smartex (by Smartex) & textile & 25 -pads & $5 \times 5$ & round & $1 \mathrm{~cm}$ & $5 \mathrm{~mm}$ & $9 \mathrm{~cm} \times 9 \mathrm{~cm}$ \\
\hline Chen & $\begin{array}{l}\text { plastic flexible } \\
\text { substrate }\end{array}$ & 30-pads & $\begin{array}{l}6 \text { rows of } \\
5 \text { pads }\end{array}$ & round & $1 \mathrm{~cm}$ & $3 \mathrm{~mm}$ & $8.5 \mathrm{~cm} \times 7.2 \mathrm{~cm}$ \\
\hline HYPER (by Tecnalia) & $\begin{array}{l}\text { plastic flexible } \\
\text { substrate }\end{array}$ & 16-pads & $4 \times 4$ & rectangular & $2.6 \mathrm{~cm} \times 0.6 \mathrm{~cm}$ & $2 \mathrm{~mm}$ & \\
\hline FEA & $\begin{array}{l}\text { screen-printed } \\
\text { flexible } \\
\text { and breathable } \\
\text { fabric }\end{array}$ & 24-pads & $4 \times 6$ & oval & $0.75 \mathrm{~cm} \times 1.25 \mathrm{~cm}$ & $0.75 \mathrm{~cm}$ & $11.5 \mathrm{~cm} \times 5.5 \mathrm{~cm}$ \\
\hline MUNDUS (by Tecnalia) & $\begin{array}{l}\text { textile + plastic } \\
\text { flexible substrate }\end{array}$ & 78-pads & $\begin{array}{l}6 \text { separated } \\
\text { arrays }\end{array}$ & rectangular & & $2 \mathrm{~mm}$ & \\
\hline
\end{tabular}

\section{Selective control of muscle activation}

Two main types of applications of surface electrode arrays for muscle stimulation have been found in the literature: i) selective control of forearm muscles through modulation of the electric field under the surface electrode and ii) management of muscle fatigue in leg muscles, through asynchronous activation of motor units. In both scenarios, the key challenge is to apply electrode arrays to selectively activate different motor units with individual pads or combinations of pads.

\section{Upper limb selective sFES applications}

Most of the studies on control of upper limb movement were focused on developing algorithms for selecting the best-located pads. Popovic et al. [52] underlined the importance of muscle fatigue in upper limb function tasks.
Table 2 contains details of sFES systems with electrode arrays in the upper limb. The following section revises the hardware platforms that have been proposed to analyze the response of sFES and addressing the selection of best-located pads over targeted muscles.

Hardware classification Different types of sensors can be applied to determine the response to stimulation. We categorized the platforms found in the literature as follows: 1) force/torque generation [53-55] and 2) kinematic generation [45, 56-61]. Kinematic sensors are becoming preferred for these purposes because of portability and simple use. Accelerometers were widely preferred in seminal works [56-58, 61], although later low-cost flex sensors were considered as an alternative $[59,60,62]$.

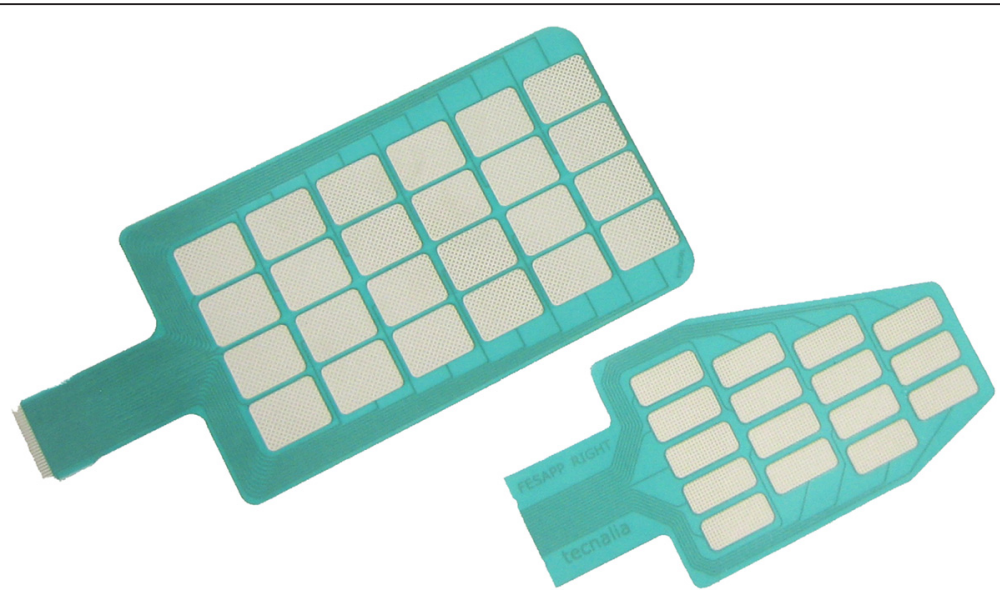

Fig. 1 Two examples of INTFES electrodes for upper limb sFES applications 
Table 2 Comparison of main selectivity study platforms found in literature

\begin{tabular}{|c|c|c|c|c|c|c|c|c|c|}
\hline Platform & $\begin{array}{l}\text { Lawrence et } \\
\text { al., } 2006[54]\end{array}$ & $\begin{array}{l}\text { O'Dwyer et al., } 2006 \\
\text { [56] }\end{array}$ & Popovic et al, 2009 [57] & $\begin{array}{l}\text { Malesevic et. al, } 2010 \\
\text { [58] }\end{array}$ & $\begin{array}{l}\text { Malesevic et al, } 2012 \\
\text { [59] }\end{array}$ & $\begin{array}{l}\text { Schill et al, } \\
2009[60]\end{array}$ & $\begin{array}{l}\text { Chen et al, } \\
2007[45]\end{array}$ & Koutsou et al, 2013 [61] & $\begin{array}{l}\text { Exell et al, } 2013 \\
{[62]}\end{array}$ \\
\hline $\begin{array}{l}\text { Array } \\
\text { Electrode }\end{array}$ & $\begin{array}{l}\text { Smart } \\
\text { Electrode } \\
\text { 64-pads }\end{array}$ & $2 \times 2$ round & $\begin{array}{l}\text { Actitrode, 24-pads, } \\
\text { round }\end{array}$ & INTFES, 16-pads, oval & INTFES, 16-pads, oval & $2 \times 3$ round & $\begin{array}{l}\text { own } \\
\text { electrode } \\
\text { array }\end{array}$ & Smartex electrode array & FEA, $4 \times 6$ round \\
\hline $\begin{array}{l}\text { Electrical } \\
\text { stimulator }\end{array}$ & $\begin{array}{l}\text { Compex } \\
\text { Motion2. 4- } \\
\text { channel } \\
\text { biphasic } \\
\text { asymmetric }\end{array}$ & $\begin{array}{l}\text { Neurotech NT2000, } \\
\text { 6-channel biphasic } \\
\text { asymmetric }\end{array}$ & $\begin{array}{l}\text { UNAFET, 4-channel } \\
\text { biphasic asymmetric }\end{array}$ & $\begin{array}{l}\text { INTEFES, 1-channel } \\
\text { with a demultiplexer } \\
\text { for } 32 \text {-pad } \\
\text { electrodes } \\
\text { monophasic } \\
\text { rectangular }\end{array}$ & $\begin{array}{l}\text { INTEFES, 1-channel } \\
\text { with a demultiplexer } \\
\text { for } 32 \text {-pad } \\
\text { electrodes } \\
\text { monophasic } \\
\text { rectangular }\end{array}$ & $\begin{array}{l}\text { MotionStim } \\
8,8 \text {-channel } \\
\text { biphasic }\end{array}$ & NM III & $\begin{array}{l}\text { INTEFES, 1-channel with } \\
\text { a demultiplexer for 32- } \\
\text { pad electrodes } \\
\text { monophasic rectangular }\end{array}$ & $\begin{array}{l}\text { Modified Odstock } \\
\text { stimulator }\end{array}$ \\
\hline $\begin{array}{l}\text { Upper Limb } \\
\text { functions }\end{array}$ & $\begin{array}{l}\text { fingers' } \\
\text { flexion }\end{array}$ & $\begin{array}{l}\text { Wrist flexion- } \\
\text { extension,abduction- } \\
\text { aduction, Fingers's } \\
\text { flexion }\end{array}$ & $\begin{array}{l}\text { Forearm pronation- } \\
\text { supination, wrist flexion- } \\
\text { extension, abduction- } \\
\text { adduction, fingers's } \\
\text { flexion-extension }\end{array}$ & $\begin{array}{l}\text { wrist flexion- } \\
\text { extension, fingers' } \\
\text { flexion-extension }\end{array}$ & $\begin{array}{l}\text { wrist flexion- } \\
\text { extension, fingers' } \\
\text { flexion }\end{array}$ & $\begin{array}{l}\text { wrist } \\
\text { flexion- } \\
\text { extension, } \\
\text { abduction- } \\
\text { adduction }\end{array}$ & $\begin{array}{l}\text { Wrist joint, } \\
\text { fingers' } \\
\text { felxion- } \\
\text { extension }\end{array}$ & $\begin{array}{l}\text { Forearm pronation- } \\
\text { supination, wrist flexion- } \\
\text { extension, abduction- } \\
\text { adduction, fingers's } \\
\text { flexion-extension }\end{array}$ & $\begin{array}{l}\text { Wrist joint, fingers' } \\
\text { felxion-extension }\end{array}$ \\
\hline Sensors & $\begin{array}{l}\text { miniature } \\
\text { load cells }\end{array}$ & $\begin{array}{l}\text { bend sensors, } \\
\text { accelelometers }\end{array}$ & goniometers & $\begin{array}{l}\text { goniometers, } \\
\text { accelelometers }\end{array}$ & bend sensors & $\begin{array}{l}\text { bend } \\
\text { sensors }\end{array}$ & CyberGlove & $\begin{array}{l}\text { bend sensors, } \\
\text { accelelometers }\end{array}$ & $\begin{array}{l}\text { Data glove, twin- } \\
\text { axis } \\
\text { electrogoniometer }\end{array}$ \\
\hline $\begin{array}{l}\text { Stimulation } \\
\text { Strategy }\end{array}$ & $\begin{array}{l}\text { Sequentially } \\
\text { activation of } \\
\text { pads region } \\
\text { during } 5 \mathrm{~s}\end{array}$ & $\begin{array}{l}\text { Sequentially } \\
\text { activation of a } \\
\text { different } \\
\text { combination of pair } \\
\text { electrodes during } 3 \\
\mathrm{~s}\end{array}$ & $\begin{array}{l}\text { Sequentially activation of } \\
\text { pads during } 4 \mathrm{~s}\end{array}$ & $\begin{array}{l}\text { Single current pulses } \\
\text { via each pad, with } \\
\text { frequency of } 2 \mathrm{~Hz} \text {. }\end{array}$ & $\begin{array}{l}\text { Sequentially } \\
\text { activation of pads } \\
\text { during } 2 \mathrm{~s}\end{array}$ & $\begin{array}{l}\text { Single } \\
\text { current } \\
\text { pulses via } \\
\text { each pad }\end{array}$ & $\begin{array}{l}\text { Sequentially } \\
\text { activation of } \\
\text { pads }\end{array}$ & $\begin{array}{l}\text { Sequentially activation } \\
\text { of pads during } 2 \mathrm{~s}\end{array}$ & $\begin{array}{l}\text { Sequentially } \\
\text { activation of pads } \\
\text { region(blocks) }\end{array}$ \\
\hline $\begin{array}{l}\text { Pad } \\
\text { Selection }\end{array}$ & $\begin{array}{l}\text { Automatic, } \\
\text { regions with } \\
\text { higher } \\
\text { forces }\end{array}$ & $\begin{array}{l}\text { Automatic, } \\
\text { comparison with } \\
\text { target movement }\end{array}$ & Automatic, cost function & Automatic, ANN & $\begin{array}{l}\text { Automatic, cost } \\
\text { function }\end{array}$ & $\begin{array}{l}\text { semi- } \\
\text { automatic, } \\
\text { cost } \\
\text { function }\end{array}$ & $\begin{array}{l}\text { non- } \\
\text { automatic, } \\
\text { pas with } \\
\text { higher } \\
\text { amount of } \\
\text { movement }\end{array}$ & Automatic, cost function & Automatic, ILC \\
\hline Portability & $\begin{array}{l}\text { NOT } \\
\text { Portable }\end{array}$ & Portable & portable & portable & portable & portable & portable & portable & portable \\
\hline
\end{tabular}


Algorithm classification Different concepts have been proposed to develop algorithms for the selection of the best-located pads. We found studies that analized the force and determined if the activated pad contracts the desired muscle $[54,55]$. Other type of systems compared the generated movement with respect to a predefined movement [56]. Also, computational algorithms have been proposed to compare the generated movement with the desired movement and use this factor to qualify the activated pad [57, 59-61]. Artificial Neural Networks (ANN) and Iterative Learning Control (ILC) were also proposed for the selection of the pads [58, 62].

\section{Lower limb selective sFES applications}

Five studies that have addressed muscle fatigue management with asynchronous selective activation of lower limb muscles were revised [63-67]. Main characteristics of these studies can be found in Table 3. We focus on two key characteristics for each study: force production assessment and stimulation strategy.

Assessment of force production Muscle fatigue can be defined in different ways. The approach adopted in Popovic et al. [63] and Malesevic et al. [66] was defined as the decrease to $70 \%$ of the maximum of the knee torque, while in Nguyen et al. [64] and Sayenko et al. [67] was defined as the decrease of $3 \mathrm{db}$ of the maximum torque. Furthermore, Sayenko et al. [65] used a group of muscle properties to study muscle fatigue as well. Different metrics have been used to assess force production: time interval before muscle fatigue appears $[63,66]$, muscle fatigue index (torque at the end of stimulation), fatigue time (time passed by until torque decreases $3 \mathrm{~dB}$ ), torque-time interval (integral of torque during stimulation time) [64, 67]. Sayenko et al. [65] used a protocol that included the following measures to describe muscle contraction and relaxation: 1 ) torque rise time in ascending phase, 2) rate of torque development in ascending phase, 3) half-relaxation time in descending phase and 4) rate of torque relaxation.

Stimulation strategies Different stimulation strategies have been proposed as a way to mimic CNS and activate asynchronously different muscles fibers and muscles. The stimulation strategies for the lower limb share the following characteristics: a) asynchronous stimulation achieved with the use of four electrodes, and b) stimulation frequency of single electrode stimulation that is close to the sum of individual stimulation frequencies of all pad electrodes. Stimulation frequencies in single electrode strategy were similar $40 \mathrm{~Hz}[63-65,67]$ and $30 \mathrm{~Hz}$ [66]. In asynchronous electrode pad strategy, each pad is activated sequentially with a delay from the previous one. Stimulation frequency of muscle group is reduced

Table 3 Comparison of main features of lower limb fatigue resistant strategies

\begin{tabular}{|c|c|c|c|c|c|c|}
\hline Fatigue strategy & $\begin{array}{l}\text { Muscle fatigue } \\
\text { definition }\end{array}$ & Fatigue metric & Muscle group & $\begin{array}{l}\text { Stimulation strategies } \\
\text { \& electrodes }\end{array}$ & Subjects & Results \\
\hline $\begin{array}{l}\text { Popovic et al. } \\
2009 \text { [63] }\end{array}$ & $\begin{array}{l}70 \% \text { decrease } \\
\text { of max torque }\end{array}$ & Fatigue Interval & Quadriceps & $\begin{array}{l}\text { Synchronous single } \\
\text { electrode vs } \\
\text { Asynchronous } \\
4 \text { smaller electrodes }\end{array}$ & $\begin{array}{l}6 \text { complete } \\
\text { SCl patients }\end{array}$ & $\begin{array}{l}150 \% \text { increase of fatigue } \\
\text { interval with electrode array }\end{array}$ \\
\hline \multirow[t]{2}{*}{$\begin{array}{l}\text { Malesevic et al. } \\
2010 \text { [58] }\end{array}$} & $\begin{array}{l}70 \% \text { decrease } \\
\text { of max torque }\end{array}$ & Fatigue Interval & Quadriceps & $\begin{array}{l}\text { Synchronous single } \\
\text { electrode vs } \\
\text { Asynchronous } \\
4 \text { smaller electrodes }\end{array}$ & $\begin{array}{l}6 \text { complete } \\
\text { SCl patients }\end{array}$ & $\begin{array}{l}\text { Synchronous: } 31 \% \text { increase } \\
\text { of post-therapy muscle } \\
\text { fatigue resistance. }\end{array}$ \\
\hline & & & & 20 daily sessions & & $\begin{array}{l}\text { Asynchronous: } 4 \% \text { increase } \\
\text { of post-therapy muscle } \\
\text { fatigue resistance. }\end{array}$ \\
\hline $\begin{array}{l}\text { Nguyen et al. } \\
2011 \text { [64] }\end{array}$ & $\begin{array}{l}\text { Torque decrease } \\
\text { of } 3 \mathrm{~dB}\end{array}$ & $\begin{array}{l}\text { Fatigue Index, } \\
\text { Fatigue Time, } \\
\text { Torque-Time- } \\
\text { Interval }\end{array}$ & Tricep Surae & $\begin{array}{l}\text { Synchronous single } \\
\text { electrode vs } \\
\text { Asynchronous } \\
4 \text { smaller electrodes }\end{array}$ & $\begin{array}{l}1 \text { complete } \\
\mathrm{SCl}\end{array}$ & $\begin{array}{l}\text { Asynchronous stimulation: } \\
\text { higher torque values for a } \\
\text { longer period of time }\end{array}$ \\
\hline $\begin{array}{l}\text { Sayenko et al. } \\
2013 \text { [67] }\end{array}$ & $\begin{array}{l}\text { Torque decrease } \\
\text { of } 3 \mathrm{~dB}\end{array}$ & Fatigue Index & $\begin{array}{l}\text { Knee flexors/ } \\
\text { extensors, } \\
\text { plantar flexor/ } \\
\text { dorsiflexor }\end{array}$ & $\begin{array}{l}\text { Synchronous single } \\
\text { electrode vs } \\
\text { Asynchronous } \\
4 \text { smaller electrodes }\end{array}$ & $\begin{array}{l}15 \text { able-bodied } \\
\text { subjects }\end{array}$ & $\begin{array}{l}\text { Asynchronous stimulation } \\
\text { higher fatigue resistant } \\
\text { than synchronous }\end{array}$ \\
\hline $\begin{array}{l}\text { Sayenko et al. } \\
2014 \text { [65] }\end{array}$ & $\begin{array}{l}\text { They studied } \\
\text { muscle contraction } \\
\text { properties }\end{array}$ & $\begin{array}{l}\text { Torque-Rise } \\
\text { Time, Rate } \\
\text { of torque } \\
\text { development, } \\
\text { Half-Relaxation- } \\
\text { Time, Rate of } \\
\text { torque relaxation }\end{array}$ & $\begin{array}{l}\text { Tricep Surae, } \\
\text { right gastrocnemius }\end{array}$ & $\begin{array}{l}\text { Synchronous single } \\
\text { electrode vs } \\
\text { Asynchronous } \\
4 \text { smaller electrodes }\end{array}$ & $\begin{array}{l}15 \text { able-bodied } \\
\text { subjects }\end{array}$ & $\begin{array}{l}\text { Amplitude of M-waves } \\
\text { depends on the location } \\
\text { of the stimulated pad } \\
\text { electrodes. Peaks on } \\
\text { M-waves on ascending } \\
\text { phase of synchronous } \\
\text { stimulation are fused } \\
\text { as fatigue occurs. }\end{array}$ \\
\hline
\end{tabular}


to $16 \mathrm{~Hz}[63,66]$ and $10 \mathrm{~Hz}[64,65,67]$, while electrode pad stimulation frequency is the same as in single electrode strategy.

\section{Discussion}

Two main materials had been used in electrode array fabrication: textile and plastic flexible substrate. Hydrogel membrane in plastic electrode arrays offers a better contact with the electrode substrate. Regardless of the electrode's material, a layer of a hydrogel membrane between the electrode and the skin is needed in order to avoid skin irritations and pain [12, 44-48]. Furthermore, the impedance of the used hydrogel membrane in combination with pad's and gap's size influence on muscle activation selectivity [68]. However, the electrode array proposed by Yang et al. [49] reported no need of use of hydrogel membrane and resulted in higher repeatability of movement than the INTFES [44].

Two of the most important characteristics of an array electrode are the size of the forearm and the design of the array [59]: the size of the array electrode should be scaled according to the size of the forearm of the patient. The design of the array structure should take into account the shape, size and position of the target muscle group in order to be able to cover all its superficial area. Kuhn et al. [39] were the first to mark the importance of the array design on muscle selectivity. The authors developed a Finite Element and a nerve model in order to find the gel resistivities and gap sizes more adequate for muscle selectivity in array electrodes. The simulation results indicated that a high resistance gel reduces the activated area under the gaps but increases muscle selectivity. Pad electrode dimension influences muscle selectivity depending on the size of the target muscle. In addition, it has been proven that the size of the electrode pad over a single muscle does not change the number of activated muscle fibers [69], but it is demonstrated that is correlated to skin irritations and pain. Control of upper limb muscles with sFES electrode arrays can be achieved with relatively low intensity $(50 \mathrm{~mA})$. On the other hand, artificial control of the lower limb muscles with surface electrodes demands higher range $(100 \mathrm{~mA})$ and thus, pad electrode design should address avoidance of skin irritations, pain and burns. Some electrode arrays were designed specifically for upper limb applications, such as in Smartex (see Fig. 2) and MUNDUS. Smartex was an upper limb garment that integrates four 25-pads electrodes arrays for EMG recordings and FES stimulation of main muscle groups of the upper limb (biceps, triceps, wrist flexors and extensors). MUNDUS consisted of six bendable embedded customizable stimulation arrays for stimulation of wrist movements. HYPER electrodes were designed and developed as a complete solution for the whole body: upper limb (see Fig. 3), lower limb (see Fig. 4), shoulder, back, and gluteus. Each electrode array was adapted to each muscle group. For

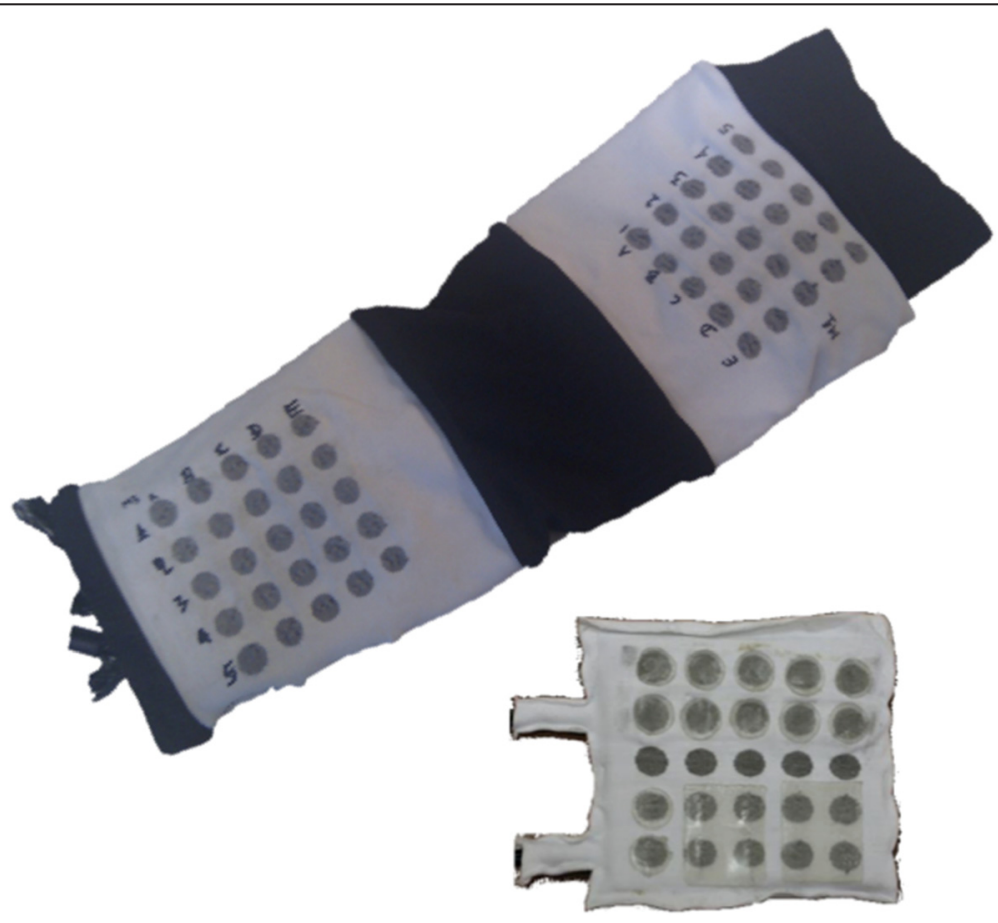

Fig. 2 Two versions of SMARTEX electrode. Single electrode array version right corner and 4-electrode array garment for full upper limb sFES applications 


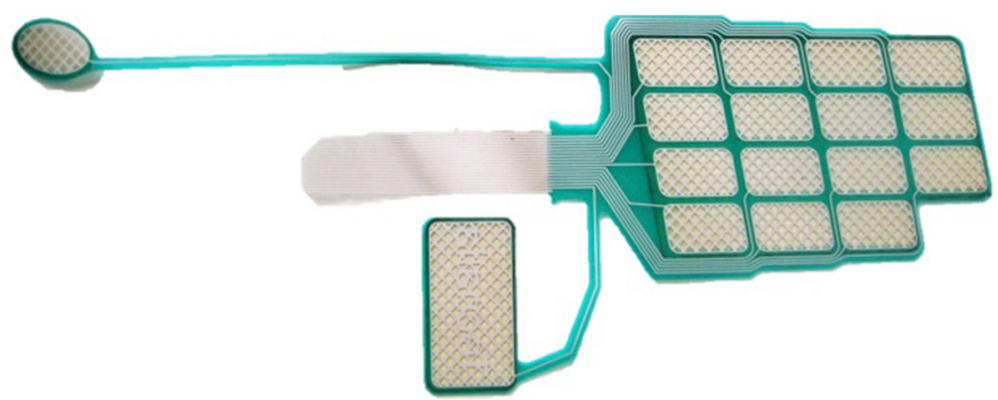

Fig. 3 HYPER electrode for right wrist extensors surface stimulation. Electrode for wrists flexors is symmetrical to this one

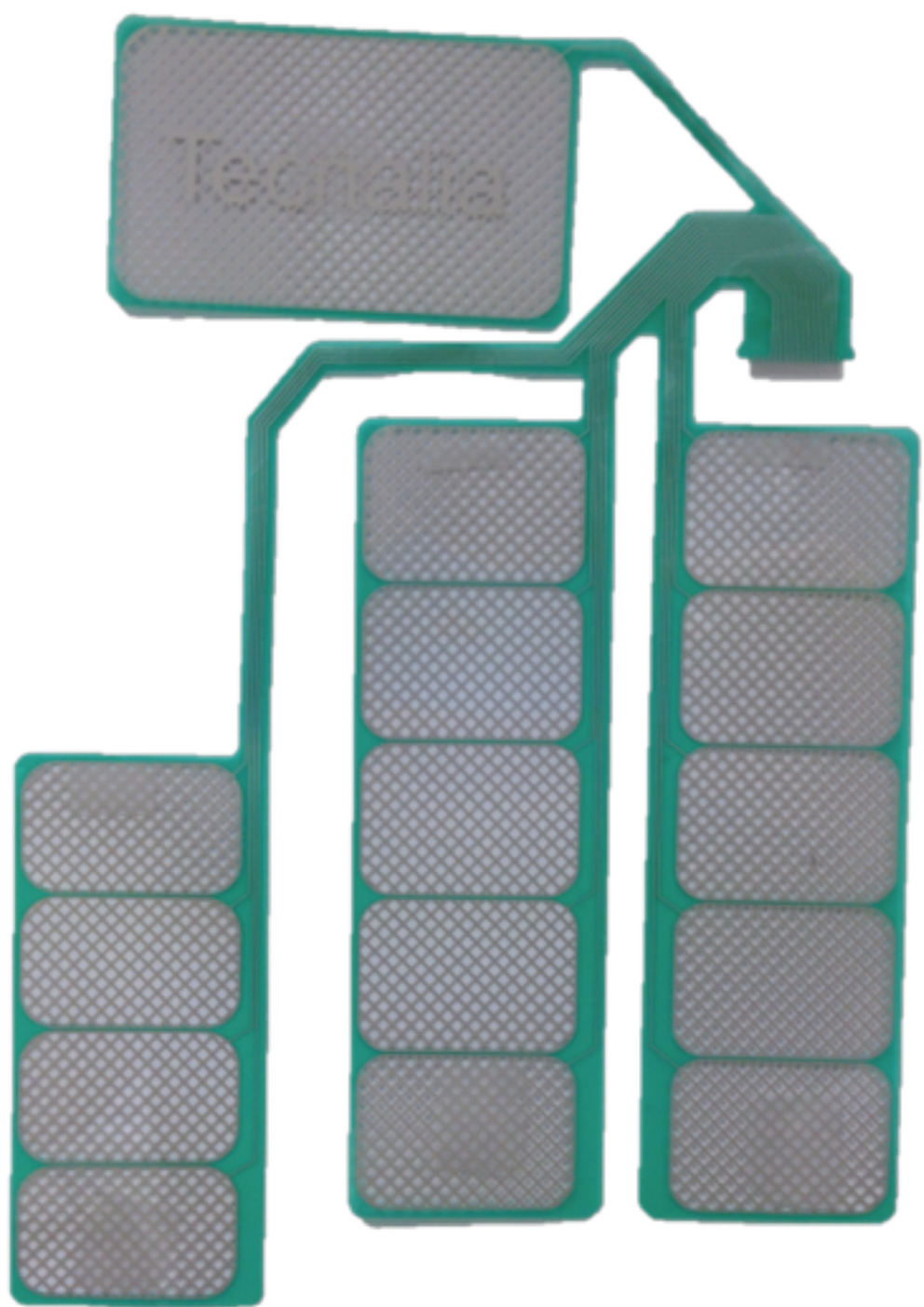

Fig. 4 HYPER electrode for lower limb quadriceps surface stimulation 
example, for wrist functions, the design was separated into: a) first part consisted of 15 pads to stimulate finger flexors or extensors and forearm pronator or supinator, and b) second part consisted of 1 pad to stimulate thumb flexors or extensors, see Fig. 3. Popovic-Maneski et al. [70] presented a very detailed work on the design of another version of the INTFES electrode for forearm sFES applications. They underline the variety of the stimulation sites between patients that resulted in designing a rather large electrode array.

The main difference between electrode arrays [12, 44, 46-49] and individual electrodes is that each pad can be independently activated and therefore can be converted in an electrode of an irregular shape. Another case is, for example, the proposed by Chen et al. [45] in which an electrode array of 30-pads was proposed that could be activated in groups of five pads on the same line. This resulted in possible active electrodes of rectangular shape but with different size.

Electrode arrays to be applied at upper limb NPs, require a custom configuration method and hardware. The stimulation strategy chosen for the configuration method drastically affect the time duration of this phase. In this regard, sequential activation of pads (or a group of pads) for a short period of seconds was the most used strategy [45, 54, 56, 57, 59, 61, 62]. However, Malesevic et al. [58] and Schill et al. [60] proposed a faster method: a single pulse stimulation strategy for each pad. Furthermore, RT-time sFES control systems need the best-located pads configuration method to be fully automatic [54, 56-59, 61, 62] in order to be able to adjust the stimulation pattern as the forearm position changes. Alternatively, other works such as Schill et al. [60] and Chen et al. [45] do proposed a different method applying semi- and non-automatic configuration methods, respectively.

Lower-limb NPs do not require complex electrode array configurations. The revised lower limb NPs with multi-pad electrodes are focused on strategies for asynchronous independent activation of pad electrodes. A common finding was that asynchronous stimulation of the pads of electrode arrays delays the appearance of muscle fatigue [63-67]. It has been demonstrated that asynchronous stimulation with electrode arrays can increase the time interval to generate fatigue up to $150 \%$ in comparison with single electrode configurations [63]. A recent study that tested this technique to promote lower limb muscle function in SCI patients confirmed this finding [66]. However, the former study concluded that electrode array should not be used in applications to train for muscle fatigue resistance.

Interestingly, an investigation [65] of asynchronous stimulation with electrode arrays on the gastrocnemius muscles in able-bodied subjects demonstrated that the amplitude of the $\mathrm{M}$-waves at each muscle portion is dependent on the location of the stimulation electrode pad. This led to suggest that different sets of muscles fibers are excited each time a different electrode pad is activated [65]. Overall results in those studies were independent of pad electrode or muscle size. Furthermore, Malesevic et al. [59] demonstrated that asynchronous activation with different FES parameters could be applied for grasping. Interestingly. Furthermore, it has been demonstrated that synchronous activation with electrode arrays may increase muscle fatigue in comparison with a single electrode of the same size due to muscle fibers that fall under the region of the gaps between pads [69]. Lastly, asynchronous stimulation needs independently activated pads and thus, the number of pad arrays that can be activated with different FES parameters should be maximized in future designs.

\section{The future of multi-pad electrode based FES}

Besides the above revised considerations, electronic design and its effects on the ability to dynamically define the stimulation parameters (e.g., pulse amplitude, shape, width, repetition frequency, train duration), are crucial to achieve efficient selective muscle activation with electrode arrays. Latest studies and advances in sFES highlight the need of flexible waveforms generators and multi-channel systems with real-time connectivity and with an independent configuration of stimulation parameters per channel. Electrode arrays can contain dozens of electrodes that have to be connected to the stimulator and moreover stable current stimulator is not trivial to design using compact electronic components. There are research prototypes attempting to solve this matter by means of custom microelectronic design. However, power management and dissipation are major concerns and still open issues in these type of prototypes [71]. Stimulators of these characteristics are at the time only available for research purposes [44, 71].

At the moment, there are no studies that include platforms of electrode arrays that account for real-time FES control and electrode array reconfiguration. In the future, the combination of closed-loop control strategies with best-located pad electrodes algorithms should be the subject of applications to control the upper limb muscles, while in the lower limb closed-loop fatigue control with low-frequency stimulation should be developed.

Finally, the studies included in this review were conducted with limited number of subjects and short intervention periods; therefore, clinical studies with larger numbers of patients and rehabilitative approaches should be conducted. 


\section{Conclusions}

Muscle activation selectivity and fatigue are the main challenges in sFES. Over the last decade several investigations have attempted to artificially induce motor unit recruitment in order to achieve high level of muscle selectivity and improved fatigue response. Research studies on upper limb NPs with electrode arrays have led to significant improvement of muscle activation selectivity. However, further studies on closed-loop control selectivity activation strategies need to be developed, clinical studies with impaired subjects are necessary in order to certify the obtained results until now and new microelectronics system stimulators are needed to be available for clinical use.

\section{Abbreviations \\ ANN, Artificial Neural Networks; CNS, Central Nervous System; EMG, Electromyography; FEA, Fabric Electrode Array; FG, Fast, Glycolytic; ILC, Iterative Learning Control; NPS, Neuro-Prostheses; PID, Proportional- Integral-Derivative; SCI, Spinal Cord Injury; sFES, Surface Functional Electrical Stimulation; SO, Slow, Oxidative.}

\section{Acknowledgements \\ This work has been done with partial financial support of the Ministry of Science and Innovation, in the framework of national project HYPER (CSD 2009-00067- Hybrid Neuroprosthetic and Neurorobotic Devices for Functional Compensation and Rehabilitation of Motor Disorders) and European Union in the framework of TREMOR Project: "TREMOR: An ambulatory $\mathrm{BCl}$-driven tremor suppression system based on functional electrical stimulation", ICT-2007-224051, and "NeuroTREMOR: A novel concept for support to diagnosis and remote management of tremor", ICT-2011.5.1-287739.}

\section{Availability of data and materials}

The data supporting the conclusions of this article are included within the article and its additional files.

\section{Authors' contributions}

AK conceived the idea of the manuscript, carried out the design of the manuscript, the study of sFES theory, the review of electrode arrays and upper muscle selectivity studies, participated in lower muscle fatigue studies review, the sequence alignment and drafted the manuscript. JM helped to draft the manuscript, participated in the design, the sequence alignment and revised the manuscript. AA participated in lower muscle fatigue studies review, revised and helped to draft the manuscript. ER revised and helped to draft the manuscript. JP revised and helped to draft the manuscript. All authors read and approved the final manuscript.

\section{Authors' information}

Aikaterini D. Koutsou acquired her Bachelor degree in Industrial Informatics Engineering at the Technological Institute of Kavala (Greece) and her Master degree on "Advanced Electronic System. Intelligent Systems" at Alcala Univerisity (Spain). She is PhD student at Neural Rehabilitation Group, Cajal Institute Spanish National Research Council. Her main research fields are functional electrical stimulation, muscle selectivity, muscle fatigue and FES control. Contact: aikaterini.koutsou@csic.es.

Juan C. Moreno is with Cajal Institute at CSIC (Spain). He received the degree in automatics engineering from U. La Salle and since 2001 he has been with CSIC, developing and studying the lower leg orthosis GAIT at the Bioengineering Group, and received the PhD in 2006. He has scientifically and technically coordinated a number of European projects in the field of assistive technologies and robotics. In 2012 Dr. Moreno has been awarded for his research track as young investigator with the TR35 Spain award by Massachusetts Institute of Technology's (MIT) journal Technology Review, for his innovative work on Wearable Exoskeletons. Dr. Moreno is Scientific Coordinator of the FP7 Project BIOMOT of the FET-Proactive initiative
"Symbiosis between humans and computers". Currently Dr. Moreno is the leader of the Human Locomotion Lab in CSIC's Neural Rehabilitation Group. His research focus is on rehabilitation of gait after neurological diseases with particular interest in stroke and spinal cord injuries. Contact: jc.moreno@csic.es.

Antonio J. del Ama has a graduate in Industrial Engineering, master in Robotics and Automation and Ph. D. from the Carlos III University. $\mathrm{He}$ is researcher at the Biomechanics and technical Aids at the National Hospital for Spinal Cord Injury in Toledo. His early work was related to the application of movement analysis to evaluation of assistive technology, mainly wheelchair propulsion and gait analysis. He was awarded by the Technological Innovation price by the Rodolfo Benito Samaniego foundation by his work in this field. Recently, he is working on rehabilitation robotics and neuroprosthetics, involved in the design and validation of lower limb exoskeletal robots and neuroprosthesis for rehabilitation of motor disorders. His current research interests include biomechanical modeling, rehabilitation robotics design and control, human-robot interaction, evaluation of assistive technology and teaching. He is also member of the Medical and Clinical Engineering Committee at the Industrial Engineers Association of Madrid (COAIM). Contact: ajdela@sescam.jccm.es.

Eduardo R. Lima was born in 1979 in Vitória, Brazil. He graduated in Electrical Engineer from Universidade Federal do Espírito Santo (UFES) in 2001. From 1999 through 2000 he was research associate at Laboratorio de Automação Inteligente (LAI) at UFES. He held a CNPq scholarship at UFES from 1999 through 2000. He received a Ph.D. degree in 2006 from the Universidad Politécnica de Madrid. His researched activity was awarded with the Georges Giralt PhD Award as the best PhD robotics thesis in Europe and the EMBEC scientific award. He is current a tenure researcher at the Bioengineering Group at the Consejo Superior de Investigaciones Científicas (CSIC). His research interests include rehabilitation, neurophysiology, biomechanics, adaptive signal processing, and human machine interaction. Contact: e.rocon@csic.es.

Prof. Jose L. Pons obtained his PhD in Physics, Universidad Complutense Madrid, in 1997. In 1998 he was appointed as Postdoctoral Fellow at the Institute for Industrial Automation of the Spanish Council for Scientific Research, CSIC. In 1999 he was awarded a position as Tenured Scientist, in 2007 a position as Research Scientist and eventually in 2008 a position as Full Professor, all of them at the same institution. Prof. J.L. Pons is with CSIC since 1993 and has actively participated in a number of National, European and International RTD projects in the area of rehabilitation robotics, new actuators and control technologies. In particular, he was co-ordinator of EU GAIT, EU MANUS and EU ESBiRRo projects. In addition he is currently co-ordinating of several national scope and European projects, e.g., EU NeuroTREMOR, Biomot, H2R and HYPER. Contact: jose.pons@csic.es.

\section{Competing interests}

The authors declare that they have no competing interests.

Consent for publication

Not applicable.

Ethics approval and consent to participate

Not applicable.

\section{Author details}

${ }^{1}$ Neural Rehabilitation Group, Cajal Institute, Spanish National Research Council, Madrid, Spain. ${ }^{2}$ National Hospital for Spinal Cord Injury, Toledo, Spain. ${ }^{3}$ Neural and Cognitive Engineering group, Centro de Automática y Robótica, CAR, Spanish National Research Council, CSIC-UPM, Madrid, Spain.

Received: 15 January 2016 Accepted: 7 June 2016

Published online: 13 June 2016

References

1. Farina D, Jensen W, Akay M. Introduction to neural engineering for motor rehabilitation. Hoboken: John Wiley \& Sons; 2013.

2. Popovic MR, Curt A, Keller T, Dietz V. Functional electrical stimulation for grasping and walking: indications and limitations. Spinal Cord. 2001; 39:403-12.

3. Popovic DB, Sinkjaer T. Control of movement for the physically disabled. London: Springer-Verlang; 2000. 
4. Meadmore K, Exell T, Hallewell E, Hughes A, Freeman C, Kutlu M, Benson V, Rogers $\mathrm{E}$, Burridge J. The application of precisely controlled functional electrical stimulation to the shoulder, elbow and wrist for upper limb stroke rehabilitation: a feasibility study. J Neuroeng Rehabil. 2014;11:1-22.

5. Pedrocchi A, Ferrante S, Ambrosini E, Gandolla M, Casellato C, Schauer T, Klauer C, Pascual J, Vidaurre C, Gföhler M, Reichenfelser W, Karner J, Micera S, Crema A, Molteni F, Rossini M, Palumbo G, Guanziroli E, Jedlitschka A, Hack M, Bulgheroni M, d'Amico E, Schenk P, Zwicker S, Duschau-Wicke A, Miseikis J, Graber L, Ferrigno G. MUNDUS project: MUltimodal Neuroprosthesis for daily Upper limb Support. J Neuroeng Rehabil. 2013;10(66):1-20.

6. Del Ama A, Gil-Agudo A, Bravo-Esteban E, Perez-Nombela S, Pons J, Moreno J. Hybrid therapy of walking with Kinesis overground robot for persons with incomplete spinal cord injury: a feasibility study. Robot Auton Syst. 2014;73:44-58.

7. Gallego JA, Rocon E, Belda-Lois JM, Pons JL. A neuroprosthesis for tremor management through the control of muscle co-contraction. J Neuroeng Rehabil. 2013;10:1-13.

8. Micera S, Keller T, Lawrence M, Morari M, Popovic D. Wearable neural prosthesis. Restoration of sensory-motor function by transcutaneous electrical stimulation. IEEE Eng Med Biol Mag. 2010;29:64-9.

9. Popovic L, Malesevic N, Popovic M. Optimization of multi-pad surface electrode: selective stimulation of wrist. EUROCON. 2009;2009:142-5.

10. Kuhn A, Keller T, Lawrence M, Morari M. The influence of electrode size on selectivity and comfort in transcutaneous electrical stimulation of the forearm. IEEE Trans Neural Syst Rehabil Eng. 2010;18:255-62.

11. Lyons $\mathrm{G}$, Leane $\mathrm{G}$, Clarke-Moloney M. An investigation of the effect of electrode size and electrode location on comfort during stimulation of the gastrocnemius muscle. Med Eng Phys. 2004;26:873-8.

12. Bijelic G, Popovic A, Jorgovanovic N, Bojanic D, Popovic DE. Actitrode: the new selective stimulation interface for functional movements in hemiplegic. Serbian J Electr Eng. 2004;1:21-8.

13. Vette AH, Masani K, Kim JY, Popovic MR. Closed-loop control of functional electrical stimulation-assisted arm-free standing in individuals with spinal cord injury: a feasibility study. Neuromodulation. 2009;12(1):22-32.

14. Ferrarin M, Palazzo F, Riener R, Quintern J. Model -based control of FESinduced single joint movements. IEEE Trans Neural Syst Rehabil Eng. 2001; 9(3):245257.

15. Micera S, Sabatini AM, Dario P. Adaptive fuzzy control of electrically stimulated muscles for arm movements. Med Biol Eng Comput. 1999;37(1):680-5.

16. Previdi C, Schauer T, Savaressi SM, Hunt KJ. Data-driven control design for neuroprostheses: a vistual reference feedback tuning (VRFT) approach. IEEE Trans Control Syst Tech. 2004;12(1):176-82.

17. Kobravi HR, Erfanian A. Decentralized adaptive robust control based on sliding mode and nonlinear compensator for the control of ankle movement using functional electrical stimulation of agonist-antagonist muscles. J Neural Eng. 2009;6(4):046007.

18. Braz GP, Russold M, Davis GM. Functional electrical stimulation control of standing and steping after spinal cord injury: a review of technical charecteristics. Neuromodulation. 2009;12(3):180-90.

19. Lynch C, Popovic M. A comparison of closed-loop control algorithms for regulating electrically stimulated knee movements in indivinduals with spinal cord injury. IEEE Trans Neural Syst Rehabil Eng. 2012:20(4):539-48.

20. Ibitoye MO, Hamzaid NA, Hasnan N, Abdul Wahab AK, Davis GM. Strategies for rapid muscle fatigue reduction during FES exercise in individuals with spinal cord injury: a systematic review. PLOS ONE. 2016;11(2):1-28.

21. Franken $\mathrm{H}$, Veltink, Fidder $\mathrm{M}$, Boom $\mathrm{H}$. Fatigue of intermittently stimulated paralyzed human quadriceps during imposed cyclical lower leg movements. J Electromyogr Kinesiol. 1993;3:3-12.

22. Karu Z, Durfee W, Barzilai A. Reducing muscle fatigue in FES applications by stimulating with N.Let pulse trains. IEEE Trans Biomed Eng. 1995;42:809-17.

23. Graupe D, Suliga P, Prudian C, Kohn K. Stochastic-modulated stimulation to slow down muscle fatigue at stimulated sites in paraplegics using functional electrical stimulation for leg extension. Neurol Res. 2000;22:703-4.

24. Maladen $\mathrm{R}$, Perumal $\mathrm{R}$, Wexler $\mathrm{A}$. Effects of activation pattern on nonisometric human skeletal muscle performance. J Appl Physiol. 2007;102: 1985-91.

25. Downey RJ, Bellman M, Sharma N, Wang Q, Gregory CM, Dixon WE. A novel modulation strategy to increase stimulation duration in neuromuscular electrical stimulation. Muscle Nerve. 2011;44:382-7
26. Ding J, Wexler A, Binder-Macleod S. A predictive model of fatigue in human skeletal muscles. J Appl Physiol. 2000;89:1322-32.

27. Ding J, Wexler A, Binder-Macleod S. Development of a mathematical model that predicts optimal muscle activation patterns by using brief trains. J Appl Physiol. 2000;88:917-25.

28. Goodall E, Frits de Breij J, Holsheimer J. Position-selective activation of peripheral nerve fibers with a cuff electrode. IEEE Trans Biomed Eng. 1996; 43:851-6.

29. Pelletier CA, Hicks AL. Muscle characteristics and fatigue properties after spinal cord injury. Crit Rev Biomed Eng. 2009;37(1-2):139-64.

30. Bigland-Ritchie B, Jones DA, Woods JJ. Excitation frequency and muscle fatigue: electrical responses during human voluntary and stimulated contractions. Exp Neurol. 1979:64:414-27.

31. Bickel CS, Gregory CM, Dean JC. Motor unit recruitment during neuromuscular electrical stimulation: a critical appraisal. Eur J Appl Physiol. 2011;111:2399-2407

32. Veltink $P$, Alsté AV. Restoration of walking for paraplegics: recent advancements and trends. Artificial electrical stimulation of myelinated nerve fibers. Amsterdam: IOS PRESS; 1992.

33. Mann M. The nervous system in action. University of Nembraska Medical Center. 1997. http://michaeldmann.net/ The\%20Nervous\%20System\%20In\%20Action.html. Accessed 10 Jun 2016.

34. Blair EA, Erlanger J. A comparison of the characteristics of AXONS through their individual electrical responses. Am J Physiol. 1933;106:524-64.

35. Gregory C, Bickel CS. Recruitment patterns in human skeletal muscle during electrical stimulation. Phys Ther. 2005;85:358-64.

36. Lynch C, Popovic M. Functional electrical stimulation. IEEE Control Syst Mag. 2008:28:40-50.

37. Burke R. Motor units: anatomy, physiology, and functional organization. Compr Physiol. 1981;345-422.

38. Kuhn A, Keller T, Lawrence M, Morari M. A model for transcutaneous current stimulation: simulations and experiments. Med Biol Eng Comput. 2009:47: 279-89.

39. Kuhn A, Keller T, Micera S, Morari M. Array electrode design for transcutaneous electrical stimulation: a simulation study. Med Eng Phys. 2009:31:945-51.

40. Keller T, Kuhn A. Electrodes for transcutaneous (surface) electrical stimulation. J Autom Control. 2008;18:35-45.

41. Nathan $\mathrm{RH}$. Functional electrical stimulation of the upper limb: charting the forearm surface. Med Biol Eng Comput. 1979;17:729-36.

42. Lawrence M, Kirstein T, Keller T. Electrical stimulation of the finger flexors using Virtual Electrodes'. Int Workshop Funct Electr Stimul. 2004;8:191-4.

43. Popovic-Bijelic A, Bijelic G, Jorgovanovic N, Bojanic D, Popovic DB, Popovic MB. Multi-field surface electrode for selective electrical stimulation. Artif Organs. 2005;29(6):448-52.

44. Velik R, Malesevic N, Popovic L, Hoffmann U, Keller T. INTFES: a multi-pad electrode system for selective transcutaneous electrical muscle stimulation. IFESS. 2011;1-3

45. Chen S, Yu C, Liu C, Kuo C, Hsu S. Design of surface electrode array applied for hand functional electrical stimulation in the variation of forearm gesture. 12th Annual Conference of the International FES Society. 2007

46. Crema A, Aprigliano F, Micera S. Wearable systems for grasping restoration. Converging clinical and engineering research on neurorehabilitation, biosystems \& biorobotics. 2012. p. 1195-8.

47. Kirstein T, Lawrence M, Tröster G. Functional Electrical Stimulation (FES) with Smart Textile Electrodes. International Workshop on new Generation Systems for eHealth. 2003

48. Caldani L, Pacelli M, Farina D, Paradiso R. E-textile platforms for rehabilitation. 32nd Annual International Conference of the IEEE EMBS. 2010.

49. Yang K, Freeman C, Torah R, Beeby S, Tudor J. Screen printed fabric electrode array for wearable functional electrical stimulation. Sens Actuators A: Phys. 2014;108-15.

50. Keller T, Lawrence M, Kuhn A. Textile neuroprosthesis garment for functional stimulation. Int Workshop Funct Elect Stimul. 2007;107-10

51. Lymberis A, Paradiso R. Smart fabrics and interactive textile enabling wearable personal applications: R\&D state of the art and future challenges. 30th Annual International IEEE EMBS Conference. 2008. p. $5270-3$. 
52. Popovic-Maneski L, Malesevic N, Savic A, Keller T, Popovic D. Surfacedistributed low-frequency asynchronous stimulation delays fatigue of stimulated muscles. Muscle Nerve. 2013;48:930-7.

53. Lawrence M, Keller T. A transcutaneous electrode measurement system. International functional electrical stimulation society conference. 2005.

54. Lawrence M, Brunschweiler A, Keller T. Multi-channel Transcutaneous Electrical Stimulation Environment. International Functional Electrical Stimulation Society Conference. 2006. p. 210-12.

55. Westerveld AJ, Schouten AC, Veltink PH, van der Kooij H. Selectivity and resolution of surface electrical stimulation for grasp and release. IEEE Trans Neural Syst Rehabil Eng. 2012;20:94-101.

56. O'Dwyer S, O'Keeffe D, Coote S, Lyons G. An electrode configuration technique using an electrode matrix arrangement for FES-based upper arm rehabilitation systems. Med Eng Phys. 2006;28:166-76.

57. Popovic D, Popovic MB. Automatic determination of the optimal shape of surface electrode: selective stimulation. J Neurosci Meth. 2009;178(1):174-81.

58. Malesevic N, Popovic L, Bijelic G, Kvascev G. Muscle twitch responses for shaping the multi-pad electrode for functional electrical stimulation. J Autom Control. 2010;20:53-7.

59. Malesevic NM, Popovic-Maneski LZ, llic V, Jorgovanovic N, Bijelic G, Keller T, Popovic DB. A multi-pad electrode based functional electrical stimulation system for restoration of grasp. J Neuroeng Rehabil. 2012;9:1-12.

60. Schill O, Rupp R, Pylatiuk C, Schulz S, Reischl M. Automatic adaption of a self-adhesive multi-electrode array for active wrist joint stabilization in tetraplegic SCI individuals. IEEE Toronto International Conference Science and Technology for Humanity(TIC-STH). 2009. p. 708-13.

61. Koutsou AD, Rocon E, Brunetti F, Moreno J, Pons J. A novel method for the analysis of forearm muscle activation by selective sFES. 18th IFESS Annual Conference 2013 "Bridging Mind and Body". 2013.

62. Exell T, Freeman C, Meadmore K, Hughes A, Hallewell E, Burridge J. Optimization of hand posture stimulation using an electrode array and iterative learning control. J Autom Control. 2013;21:1-5.

63. Popovic L, Malesevic N. Muscle Fatigue of Quadriceps in Paraplegic: Comparison between Single vs. Mutli-pad Electrode Surface Stimulation. 31st Annual International Conference of the IEEE EMBS. 2009. p. 6785-88.

64. Nguyen R, Masani K, Micera S, Morari M, Popovic MR. Spatially distributed sequential stimulation reduces fatigue in paralyzed triceps surae muscles: a case study. Artif Organs. 2011;35:1174-80.

65. Sayenko D, Nguyen R, Popovic MR, Masani K. Reducing muscle fatigue during transcutaneous neuromuscular electrical stimulation by spatially and sequentially distributing electrical stimulation sources. Eur J Appl Physiol. 2014;114:793-804.

66. Malesević NM, Popović LZ, Schwirtlich L, Popović DB. Distributed lowfrequency functional electrical stimulation delays muscle fatigue compared to conventional stimulation. Muscle Nerve. 2010;42:556-62.

67. Sayenko D, Popovic M, Masani K. Spatially distributed sequential stimulation reduces muscle fatigue during neuromuscular electrical stimulation. Conf Proc IEEE Eng Med Biol Soc. 2013;3614-17.

68. Koutsou AD, Rocon E, Pons J. Does anode position and electrode impedance affect muscle selectivity in upper limb sFES? Converging Clinical and Engineering Research on Neurorehabilitation. Part I. 2012.

69. Kim J, Trew M, Pullan A, Röhrle O. Investigating the influence of multi-array electrode configurations and functional electrical stimulation protocols on skeletal muscle fatigue. Comput Biol Med. 2012.

70. Popovic-Maneski L, Kostic M, Keller T, Mitrovic S, Konstantinovic L, Popovic D. Multi-pad electrode for effective grasping: design. IEEE Trans Neur Sys Reh Eng. 2013;21(4):648-54.

71. Brunetti F, Garay A, Moreno JC, Pons J. Enhancing functional electrical stimulation for emerging rehabilitation robotics in the framework of hyper project. IEEE International Conference on Rehabilitation Robotics. 2011.

\section{Submit your next manuscript to BioMed Central and we will help you at every step:}

- We accept pre-submission inquiries

- Our selector tool helps you to find the most relevant journal

- We provide round the clock customer support

- Convenient online submission

- Thorough peer review

- Inclusion in PubMed and all major indexing services

- Maximum visibility for your research

Submit your manuscript at www.biomedcentral.com/submit
() BioMed Central 